\title{
Mechanical Properties of FeCr-Based Composite Materials Elaborated by Liquid Metal Dealloying towards Bioapplication
}

\author{
Morgane Mokhtari, Christophe Le Bourlot,* Jannick Duchet-Rumeau,* Eugénie Godet, \\ Pierre-Antoine Geslin, Sylvain Dancette, Takeshi Wada, Hidemi Kato, and Eric Maire
}

\begin{abstract}
Liquid metal dealloying (LMD) is a new technology to create porous materials. From a $(\mathrm{FeCr})_{x}-\mathrm{Ni}_{1-x}$ precursor, it is possible to get a bicontinuous structure of $\mathrm{FeCr}$ and $\mathrm{Mg}$ : a metal-metal composite. An etching step removes the $\mathrm{Mg}$ solidstate solution phase to give a metal-air composite. The last step, polymer infiltration, gives metal-polymer composites. Herein, metal-metal, metal-air, and metal-polymer (rubbery or glassy polymers) with three different phase ratios are elaborated by LMD from $\mathrm{Ni}$-based precursors and their mechanical properties are analyzed. A full polymer infiltration into the pores is obtained and the epoxy polymer properties are not affected by the metallic foam presence. Concerning control of the mechanical properties, the material's second-phase selection is a key factor. Herein, it is shown that the mechanical properties are easily designed by optimizing phase ratio, ligament size, and second-phase type and that these materials are promising materials for biomedical applications.
\end{abstract}

\section{Introduction}

Porous materials and nanoporous metals in particular have attracted considerable attention for their excellent functional properties including a high catalytic activity, sensing capabilities, and surface-enhanced Raman scattering. This is due to their interconnected structure and high specific surface ${ }^{[1-6]}$ or more recently as biomaterials. ${ }^{[7-11]}$
In contrast to conventional chemical or electrochemical dealloying which may only be applied on noble metals, liquid metal dealloying (LMD) is a promising technique for obtaining nanoporous common materials. ${ }^{[12]}$ The LMD method is a selective dissolution phenomenon of a solid alloy precursor. One component (referred to as the soluble component) is soluble in the metallic melt whereas the other (referred to as the targeted component) is not. When the solid precursor is immersed in the metallic melt, only atoms of the soluble component dissolve into the melt inducing a spontaneously organized bicontinuous microstructure formed by the targeted and sacrificial phases (solidified metallic bath). After cooling down to room temperature, the material is considered as a metal-metal composite. The sacrificial phase can be removed by subsequent selective chemical etching to obtain the final porous material with the targeted composition. This porous material is considered as a metal-air composite (it is indeed an open-cell micro/nanofoam).

Porous materials show asymmetrical behavior between tensile and compression tests. Because dealloyed samples are lowdensity materials, when densification occurs in compression testing, they present ductile behavior and a high strain to fracture. ${ }^{[13,14]}$ At the nanoscale, dealloyed samples show plasticity whereas at the macroscale the fracture behavior is rather brittle, especially in tensile testing. For nanoporous gold dealloyed from $\mathrm{Au}-\mathrm{Ag}$ precursors, the fracture behavior depends on the residual $\mathrm{Ag}$ amount. For a low residual amount, the fracture is smooth whereas for a high residual amount, the fracture follows grain boundaries. Dealloying occurred quicker into the grain boundary so the residual Ag is trapped into the ligaments, showing that grain boundaries are more porous and weaker than ligaments and break easily, therefore leading to intergranular fracture. It was also shown that increasing the residual amount of Ag will also increase Young's modulus..$^{[1,15]}$ Experiments and simulations show a high dislocation activity that makes the acquisition of a coherent and macroscopic plasticity somewhat problematic. $^{[16-18]}$

The general mechanics of porous materials is described by Gibson and Ashby where only the macroscopic behavior is taken into account. ${ }^{[19]}$ However, the nanoscale effects of the structure 
on the macroscopic material, such as the action of capillary forces, the plastic behavior of the ligaments, and ligament size, are not taken into account in such a simple analytical approach. ${ }^{[20]}$ Many reports show an increasing yield stress with decreasing ligament size. ${ }^{[21,22]}$ To take the ligament size effect into account, a Hall-Petch relationship for the yield stress calculation was introduced. ${ }^{[22]}$ However a similar scaling law for Young's modulus has not been established yet.

To improve the ductility of these porous materials, one solution is to create composite materials either by not removing the metal phase of the bicontinuous structure or by polymer infiltration of inside the pores. ${ }^{[9-11,23-25]}$ Polymer infiltration appears to provide the most promising result; however, polymer infiltration and polymer properties have yet to be properly characterized.

FeCr alloys and more generally Fe-based alloys are widely used industrially as structural and functional materials. They are readily available, affordable, and abundant metals. In a recent study, the mechanical properties of a $\mathrm{Fe}-\mathrm{Mg}$ composite elaborated by LMD was investigated. However, this study was limited to one $\mathrm{Fe} / \mathrm{Mg}$ ratio. ${ }^{[26]}$ In other previous studies, porous $\mathrm{FeCr}$ with different densities were elaborated by LMD and the resulting microstructure was characterized. ${ }^{[27-29]}$ However, the mechanical property measurements on FeCr-based composite materials elaborated by LMD are yet to be investigated. Moreover, the possibilities and the advantages in terms of the mechanical properties of polymer infiltration have not been verified. This study will characterize polymer infiltration present the experimental mechanical results and open perspectives on the use and the design of these new materials.

In this study we aim 1) to create metal-metal (FeCr-Mg), metal-air (FeCr-air), and metal-polymer (FeCr-glassy polymer and FeCr-rubbery polymer) composites by liquid metal dealloying in the $\mathrm{Mg}$ bath from three $\mathrm{FeCrNi}$ precursors $\left(\left(\mathrm{Fe}_{0.8} \mathrm{Cr}_{0.2}\right)_{x} \mathrm{Ni}_{100-x}\right.$ with $\left.\left.x=30,50,70\right) 2\right)$ to characterize polymer infiltration 3 ) and measure the resulting mechanical properties by nanoindentation and compression tests.

\section{Results and Discussion}

\subsection{Metal Phase Morphology}

The morphology of the metallic phase was preserved along the process; therefore, phase characteristic parameters were constant for each composite. From the scanning electron microscope (SEM) images, the characteristic lengths of the different composite materials and the phase ratios were measured. Results are shown in Table 1. These values are consistent with those obtained in a previous study from X-ray tomography acquisitions with a similar elaboration process. ${ }^{[28]}$ For more details about

Table 1. Materials characteristic lengths.

\begin{tabular}{lccc}
\hline Precursor & $(\mathrm{FeCr})_{30} \mathrm{Ni}_{70}$ & $(\mathrm{FeCr})_{50} \mathrm{Ni}_{50}$ & $(\mathrm{FeCr})_{70} \mathrm{Ni}_{30}$ \\
\hline \%vol FeCr phase & $28 \pm 3$ & $52 \pm 3$ & $78 \pm 3$ \\
FeCr phase thickness $[\mu \mathrm{m}]$ & $4.7 \pm 0.2$ & $4.9 \pm 0.1$ & $4.9 \pm 0.1$ \\
Second-phase thickness $[\mu \mathrm{m}]$ & $7 \pm 1$ & $4 \pm 1$ & $2 \pm 1$ \\
\hline
\end{tabular}

metal phase morphology, please refer to this previous study. ${ }^{[28]}$ The FeCr phase thickness was independent of the amount of $\mathrm{Ni}$ and was controlled by dealloying time and temperature. The amount of Ni remaining in the Mg phase was too low to be detected by SEM-EDX analysis in the FeCr phase.

In the rest of the manuscript, the materials after dealloying will be referred to using their approximate volume phase fraction and second phase, i.e., $30 \% \mathrm{FeCr}-70 \% \mathrm{Mg}$ corresponds to metalmetal (FeCr/Mg) composite elaborated from $(\mathrm{FeCr})_{30} \mathrm{Ni}_{70}$ precursor.

\subsection{Polymer Infiltration}

After polymer infiltration, measurements were carried out to check the efficiency of the infiltration process. First thermogravimetric analysis (TGA) measurements were carried out to measure the weight of the polymer inside the metal matrix. The volume of air could be calculated from the material density and weight. Then the mass of polymer was calculated considering that whole air was fully replaced by polymer. This value was considered as the theoretical polymer mass. The filling ratio was defined as the ratio of the calcined polymer mass divided by theoretical polymer mass. The measured filling ratio by TGA was $98 \pm 3 \%$. To confirm this value, some SEM images were acquired as shown in Figure 1a. This sample is a 30\% FeCr-70\% rubbery polymer. The light gray corresponds to the $\mathrm{FeCr}$ phase, the dark gray to the polymer, and some pores at the metalpolymer interface are visible (one of them is highlighted by a red circle). The filling ratio calculated from these surface observations was about $96 \pm 5 \%$, consistent with TGA measurements.

Two methods were used to check if the polymer is well polymerized. A small piece of neat polymer and metal-polymer composite was immersed in tetrahydrofuran for $10 \mathrm{~min}$ in an ultrasonic cleaning bath. Their weight was measured before and after immersion. The prepolymer epoxy, i.e., Diglycidyl Ether of Bisphenol A, is soluble in tetrahydrofuran but after thermal curing, the resulting epoxy-amine network is no longer present. ${ }^{[30]}$ Therefore if the DGEBA prepolymer is still present, a weight change before and after solubilization must be observed, meaning that polymerization was not completed. However, in our case, for both reactive systems, no weight change was observed which suggests full polymerization.

The glass transition temperatures $\left(T_{\mathrm{g}}\right)$ were measured from differential scanning calorimetry (DSC) curves to check the effect of the metallic matrix presence on polymerization (cf. Figure 1b). The results are shown in Table 2 . The DSC capsule allows only a $5 \mathrm{mg}$ sample; therefore, when the metallic foam was analyzed, the amount of polymer was low (around $1 \mathrm{mg}$ ). The glass transition was less visible on the DSC curve for a metal-polymer composite which induces larger errors on glass transition temperature measurements. Glass transition values were consistent with those in the previous literature for both systems which show that the epoxy polymers were not affected by the metallic foam presence. ${ }^{[31,32]}$ This suggests the absence of interaction between FeCr ligaments and polymer networks, contrary to what may be observed, for instance, in some epoxy networks reinforced with fibers or nanoparticles. ${ }^{[30,33]}$ 
(a)



(b)

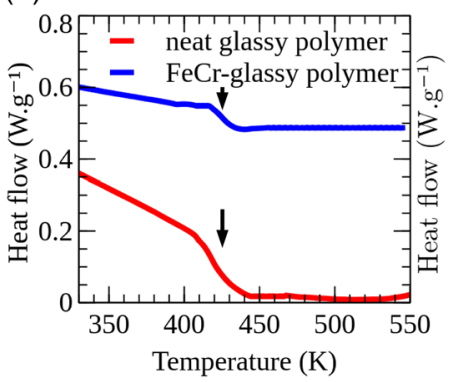



Figure 1. a) SEM image after rubbery polymer infiltration. The red circle highlights a pore at the metal-polymer interface. b) DSC curves of both systems comparing neat polymers with metal-polymer glass transition temperature (highlighted by arrows), for both polymers.

Table 2. Influence of the metal matrix on polymer glass transition temperature $\left(T_{\mathrm{g}}\right)$.

\begin{tabular}{lcc}
\hline & $\begin{array}{c}\text { Rubbery polymer } \\
\text { network } T_{\mathrm{g}}\left[{ }^{\circ} \mathrm{C}\right]\end{array}$ & $\begin{array}{c}\text { Classy polymer } \\
\text { network } T_{\mathrm{g}}\left[{ }^{\circ} \mathrm{C}\right]\end{array}$ \\
\hline Neat polymer & $-43 \pm 1$ & $144 \pm 2$ \\
Metal-polymer composite & $-44 \pm 3$ & $141 \pm 4$ \\
\hline
\end{tabular}

Polymerization inside the metallic foam was then successful and the glass transition temperature was not affected by the metallic foam.

\subsection{Mechanical Properties}

After the material's morphology characterization, the resulting mechanical properties are investigated in this section.

\subsubsection{Nanoindentation Tests}

Even though when using nanoindentation the interaction area should be considered ten times the indentation depth and using microfoam for increased accuracy, we decided to include several ligaments under the indent. ${ }^{[3]}$ To check if the indentation depth was sufficient to include several ligaments, SEM observations were conducted after nanoindentation experiments. Some images are shown in Figure 2a. Even for the lowest concentration of $\mathrm{FeCr}$ phase $(30 \% \mathrm{FeCr})$, the indent position, shown by red dashed lines, includes more than one ligament. The measured behavior was thus expected to be global for all samples.

Composite materials' theoretical Young moduli are usually bound by the Voigt and Reuss mixing law. In this study, ligaments are present an isotropic distribution. Therefore, to refine the rule of mixture, experimental results will instead be compared using the Hashin and Shtrikman (H\&S) model, which is more accurate in the case of isotropic material. Nevertheless, this model was established for spherical inclusion in a matrix and not for interpreting phase materials.

Figure $2 \mathrm{~b}$ shows the evolution of the Young's modulus as a function of $\mathrm{FeCr}$ volume phase fraction for $\mathrm{FeCr}-\mathrm{Mg}$, $\mathrm{FeCr}-$ air, and FeCr-glassy polymer composites. Dots correspond to experimental points and dashed lines to $H \& S$ boundaries. In addition to the comparison with an H\&S model, Young moduli were obtained with a spectral micromechanical approach to take into account the fact that both phases are interpenetrating. ${ }^{[39]}$ The numerical microstructure considered for these calculations are dealloyed structures obtained from a phase field model by spinodal decomposition conducted with a phase field model. ${ }^{[26]}$ Results are represented by the continuous lines in Figure 2b. Some measurements were also carried out on FeCr-rubbery polymer composites. However, this epoxy network was very soft with rubbery behavior at room temperature similar to elastomer, and indentations were subsequently unsuccessful.

Considering the simulated values, the fixed point ${ }^{[39,40]}$ used to solve the mechanical equilibrium fails to converge if the contrast between the different phases is high for low volume fractions, which explains why the numerical results do not span the composition range. Moreover, the numerical results are found to be close to the upper bound of Ha\&S, which could be attributed to the interfacial regions between both phases where the elastic constants are interpolated. ${ }^{[26]}$ This interpolation is necessary to ensure the numerical stability of the spectral method.

When considering the experimental results, all measured Young moduli were included with boundary curves expressed by H\&S boundaries. The Young moduli increased when the FeCr volume phase fraction increased as expected. In addition, the stiffness was higher for metal-metal than metal-polymer composites even if metal-polymers were stiffer than porous samples. This proves that it is possible to reinforce the porous phase by polymer infiltration, as it was already observed with infiltration by nanoporous gold and porous Ti-based alloys polymers. ${ }^{[9,10,24,25]}$

However, our experimental Young moduli (cf. Figure 2b) were lower than the simulated values. In the simulation, perfect interfaces were considered. Due to mechanical polishing, the experimental interfaces were far from perfect ((cf. Figure 2a) $70 \%$ FeCr-30\%glassy polymer) and this could explain a portion of the difference. The FeCr phase is similar for $50 \% \mathrm{FeCr}-50 \%$ $\mathrm{Mg}$ and $50 \% \mathrm{FeCr}-50 \%$ glassy polymers; however, simulated values for $50 \% \mathrm{FeCr}-50 \% \mathrm{Mg}$ are included in the errors bars of the experimental values. This is not the case for $50 \% \mathrm{FeCr}-50 \%$ glassy polymers that show the effects of pore presence at the metalpolymer interface (cf. Figure 1a). In this study we measured the Young's modulus for $30 \% \mathrm{FeCr}-70 \% \mathrm{Mg}$ of $70 \pm 10 \mathrm{GPa}$ which is consistent with the value obtained by Okulov and 
(a)



(b)

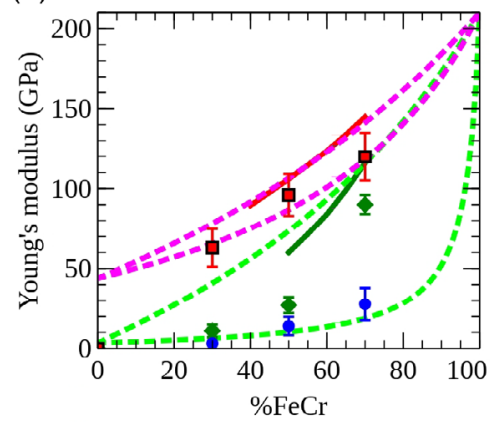

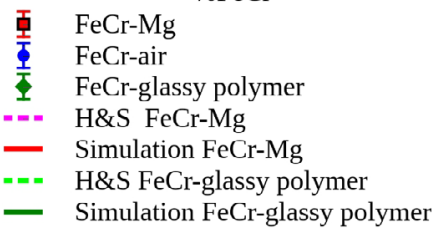

(c)

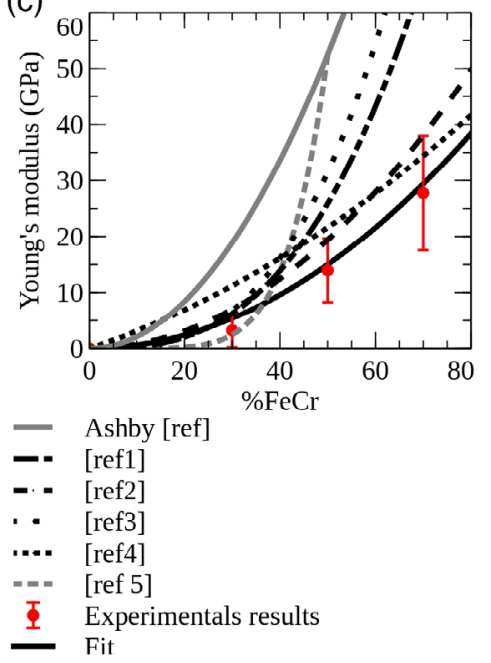

Figure 2. a) SEM image after nanoindantation test. Indents positions are highlighted by red dashed lines. b) Experimental Young moduli for metal-metal, metal-air, and metal-glassy polymer composites with various phase ratios. Dashed lines correspond to boundaries of the Hashin and Shtrikman model (H\&S) and continuous lines to values obtained by simulation. c) Experimental Young moduli of different density porous FeCr compared with different models from the literature. ${ }^{[19,35-38]}$

coworkers on Fe-Mg composites prepared by liquid metal dealloying from a $\mathrm{Fe}_{30} \mathrm{Ni}_{70}$ precursor. ${ }^{[26]}$

FeCr-Mg values present a large standard deviation which can be partially explained by the effect of surface preparation. Nanoindentation is very sensitive to surface preparation, and composites are very difficult to polish. ${ }^{[41]}$ In addition, the local composition, especially Ni-rich regions in the $\mathrm{Mg}$ phase (the presence of eutectic structure in the $\mathrm{Mg}$ phase, cf. Figure 2a), can affect the nanoindentation results. ${ }^{[3]}$

As explained in the introduction, the theoretical Young modulus and yield stress established by Gibson and Ashby are not valid for dealloyed materials. A scaling law to calculate theoretical yield stress was established. Yet, there is actually no reference model to predict the Young's modulus of nanoporous materials produced by dealloying.

In Figure 2c, the experimental values of metal-air composites are compared with existing models. The dots are experimental data. In the following equations, $E_{\rho}$ corresponds to the Young's modulus of porous materials, $E$ to that of bulk materials and $\rho$ to the relative density.

The [Ashby] referred curve corresponds to the standard Gibson and Ashby model for porous materials. ${ }^{[19]}$ This law validates up to $30 \%$ porosity. $C$ and $n$ from Equation (1) are constant and usually $C=1$ and $n=2$ for open-cell materials. ${ }^{[19]}$

$E \rho=C \rho^{n} E$

Curves plotted from previous studies ${ }^{[1-3]}$ correspond to various fittings of the Gibson and Ashby law with the case of $C=0.86$ and $n=2.8,^{[36]} C=0.37$ and $n=2,^{[37]}$ and $C=1.2$ and $n=3$, respectively. ${ }^{[38]}$ The curve plotted from a previous study $^{[4]}$ corresponds to a generalization of Gibson and Ashby's law for pure bending behavior, as shown in Equation (2)

$E p=\left(C_{1} \rho^{2}+C_{2} \rho\right) E$ where $C_{1}$ and $C_{2}$ correspond to the bending and tensile deformation modes of ligaments, respectively, and were estimated to be equal to 0.14 and 0.97 for nanoporous gold. ${ }^{[42]}$

In previous literatures, most experimental results show those lower than expected. This is due to the ligament lower structure interconnectivity and the noncontribution of some to mechanical properties. To take this contribution into account, some studies suggest the use of an apparent density instead of the real one. ${ }^{[43-46]}$ The curve plotted from a previous study ${ }^{[5]}$ on Figure 2 corresponds to Gibson and Ashby's law, where instead of taking the real density of the foam, they took the apparent density which was estimated at $4 \rho^{3}$ when the real density is below $50 \% .^{[43]}$

Gibson and Ashby's law was not valid for our materials even for low density (cf. Figure 2b). Scaling laws established for nanoporous metals were closer to the experimental values than Gibson and Ashby's law but none of them were a perfect fit for the present values. Most of these predictions were established with tensile tests, with lower-density nanoporous gold and smaller ligaments. Recent studies show that the elastic modulus in tensile/compression should be very close; however, the material's density and ligament size are important parameters, which is why all the models overestimate our experimental results. ${ }^{[44]}$ However, the one which takes into account the apparent density rather than the real density fits well with our lower-density materials, which is consistent with the low connectivity measured for these materials. ${ }^{[28,43]}$

The continuous black line corresponds to the fit of our results by Equation (3), corresponding to a generalization of Gibson and Ashby's law for a nonpure bending behavior.

$E \rho=\left(C_{1} \rho^{n}+C_{2} \rho\right) E$

We found $C_{2}=0$ and $C_{1}=0.33$ and $n=2.5$ were good parameters to best fit our results. The value $C_{2}=0$ corresponds to a pure bending behavior. 


\subsubsection{Compression Tests}

To gain a better understanding of the mechanical behavior, compression tests were conducted. The compression test curves conducted on samples with a phase ratio of $50 \% \mathrm{FeCr}$ are found in Figure 3a. For comparison, curves for neat polymers are also plotted.

The hierarchy of mechanical resistance was the same as that for Young's modulus. As expected, the stress-strain curves corresponding to $\mathrm{FeCr}-\mathrm{Mg}$ are above the other samples. FeCr-glassy composite curves are above the porous one. The reinforcing effect of a rubbery polymer addition is indeed negligible. Comparable results were obtained for other phase ratios. Glassy and rubbery polymers can be seen as having two extreme behaviors. By tuning the polymer properties, one can in principle adjust the composite properties that may be ruled anywhere between the two curves.

Figure $3 \mathrm{~b}$ shows the compression curves of all porous samples with a continuous line. In the case of $50 \% \mathrm{FeCr}-50 \%$ air and $70 \%$ FeCr-30\%air, the elastic deformation before the yield strength was visible even if not very extended, whereas for $30 \mathrm{FeCr}$, only a plastic deformation was visible. Such a low yield strength was also observed for nanoporous gold with large ligaments and similar densities. ${ }^{[21,24,25]}$

Metal-metal and metal-polymers showed a very different plastic behavior. Compared with metal-glassy polymer composites, the metal-metal composite had a higher yield stress, but the maximum stress of the metal-metal composite was close to the yield stress and samples after experiments exhibited considerable damage (crack) due to the brittle Mg phase. On the other hand, metal-glassy polymer composites had a low yield stress but stress continued to increase due to significant work hardening after yielding during the compression test. This hardening is so important that it overcomes the strength of metal-metal composites for strains larger than 0.3 .

For each load-unload cycle of each curve of Figure 3b, the Young's modulus was extracted and divided by the maximum

Young's modulus measured during the same experiment and was plotted with dots. In the case of $70 \% \mathrm{FeCr}-30 \%$ air, a small densification occurred leading to a small increase in the modulus whereas for $30 \% \mathrm{FeCr}-70 \%$ air and $50 \% \mathrm{FeCr}-50 \%$ air, a large densification occurred. During densification, the mechanical properties increase. The same phenomena were also observed with other nanoporous metals made by dealloying. ${ }^{[10,21]}$

From compression curves, when it was possible, the yield stress was extracted and the values are shown in Table 3. The same evolution as for Young's modulus was observed: mechanical properties increase when the amount of $\mathrm{FeCr}$ phase increases and when we replace air by glassy polymers or glassy polymers by metal.

\subsubsection{Comparison with Literature}

To compare the materials of this study with other materials and more specifically materials made by dealloying, mechanical results can be presented on an Ashby map: Young's modulus versus yield stress, Ashby maps are shown in Figure 3c. Materials from this study are represented by small colored dots, experimental results on dealloyed-based materials from literature studies are represented with gray circles. ${ }^{[10,11,26]}$ The yield stress is very sensitive to the ligament size; therefore, only materials with the same range of ligament size are displayed here. ${ }^{[22]}$ The influence of $\mathrm{Cr}$ addition to the mechanical properties is weak because our experimental point $30 \% \mathrm{FeCr}-70 \% \mathrm{FeCr}$ is close to that obtained from a $\mathrm{Fe}_{0.3} \mathrm{Ni}_{0.7}$ precursor. ${ }^{[26]} \mathrm{All} \mathrm{FeCr}-\mathrm{Mg}$ and $70 \% \mathrm{FeCr}-30 \%$ glassy polymers are located close to the metal

Table 3. Materials yield stress extracted from compression curves.

\begin{tabular}{lccc}
\hline Yield stress [MPa] & $30 \% \mathrm{FeCr}-70 \% \mathrm{X}$ & $50 \% \mathrm{FeCr}-50 \% \mathrm{X}$ & $70 \% \mathrm{FeCr}-30 \% \mathrm{X}$ \\
\hline $\mathrm{X}=\mathrm{Mg}$ & $190 \pm 10$ & $380 \pm 30$ & $600 \pm 30$ \\
$\mathrm{X}=$ air & $/$ & $70 \pm 30$ & $150 \pm 20$ \\
$\mathrm{X}=$ glassy polymer & $75 \pm 20$ & $/$ & $180 \pm 20$ \\
\hline
\end{tabular}

(a)

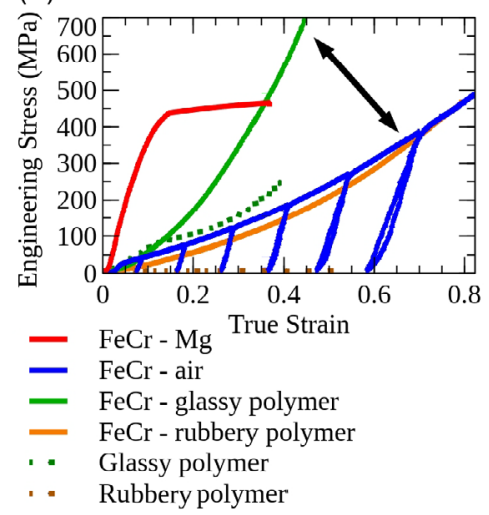

(b)

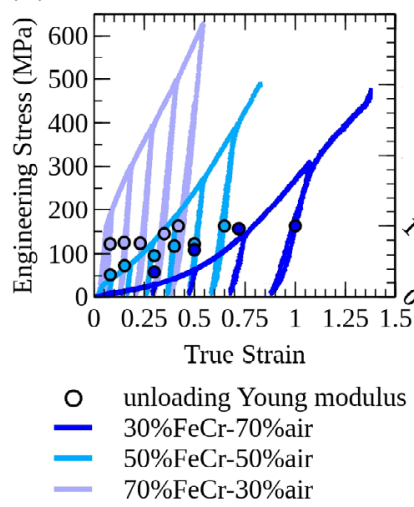

(c)

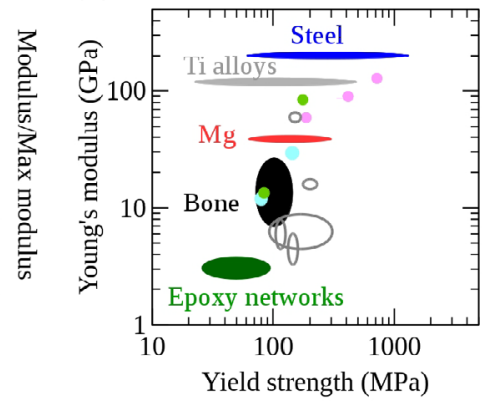

- FeCr-Mg FeCr-air • FeCr-glassy expoxy

- TiZr-air, TiHf-air, TiHf-polymer, Fe-Mg [ref]

Figure 3. a) Compression stress-strain curves for metal-metal, metal/air, metal-polymer with a metal phase volume ratio of $50 \%$ and for neat polymers. b) Compression stress-strain curves for metal-air composites with load/unload cycle. For each cycle, Young's modulus was measured and divided by the highest one and is represented by dots. c) Comparison of different materials using Ashby's map: Young's modulus versus Yield stress. Materials from this study are represented by small colored dots, experimental results on dealloyed-based materials from literature studies are represented with gray circles. $^{[10,11,26]}$ Large ellipses correspond to regions on Asbhy's maps for steel, $\mathrm{Mg}$, bone and glassy epoxy networks for dark blue, red, black, and green respectively. 
area. However, metal-air composites and metal-polymer composites with a low amount of metal are very close to other dealloyedbased materials and even to bone.

\section{Conclusion}

In this paper, metal-metal, metal-air, and metal-polymers with three different phase ratios and two different polymer types were elaborated by LMD from Ni-based precursors. Full polymer pore infiltration was successful using two different epoxy-amine networks (rubbery and glassy networks). Polymer properties were not affected by the metallic foam. Then, the mechanical properties of different composites were investigated by nanoindentation and compression. Metal-metal and metal-glassy polymers' Young moduli were included in Hashin and Shtrikman boundaries but were lower than simulated values due to the presence of imperfect interfaces and damage.

Measured metal-air Young moduli were also lower compared with those predicted by different models. The hypothesis of a pure bending behavior was made and a more relevant fitting expression to this loading mode was suggested. The experimental results fit considerably better. The mechanical behaviors of porous metal-metal composites and metal-polymer composites with a high metal phase fraction were somewhere in between those of steel and Mg alloys on Ashby maps. The Young's modulus of the porous sample could reach the value of $30 \mathrm{GPa}$ for a density of $70 \%$. The mechanical behavior of the metal-air and metal-polymer was consistent with other dealloyed-based materials and are close to bone mechanical properties, possibly leading to bioapplications.

The choice of the polymer was important for mechanical properties. In the worst case scenario, polymer filling just helped manipulate the samples (which become less brittle when infiltrated); in the best case scenario, the mechanical properties are improved.

It is thus demonstrated that the mechanical properties can be easily optimized and designed by optimizing phase ratio, ligament size, and second-phase type.

\section{Experimental Section}

Sample Elaboration: $\mathrm{A} \mathrm{Fe}-\mathrm{Cr}-\mathrm{Ni}$ alloy (the precursor) and a $\mathrm{Mg}$ molten bath were used in this study. The strategy for selecting the precursor and molten bath element is described in a previous study. ${ }^{[12]}\left(\mathrm{Fe}_{0.8} \mathrm{Cr}_{0.2}\right)_{30} \mathrm{Ni}_{70}$, ( $\mathrm{Fe} 0.8 \mathrm{Cr} 0.2){ }_{50} \mathrm{Ni}_{50}$ and ( $\left.\mathrm{Fe} 0.8 \mathrm{Cr} 0.2\right){ }_{70} \mathrm{Ni}_{30}$ ingots were prepared using arc melting as described previously. ${ }^{[27,28]}$ The resulting precursors of around $1 \mathrm{~cm}$ thickness were cold rolled until reaching $1 \mathrm{~mm}$ thickness. For LMD, cold-rolled precursors in the form of $1 \mathrm{~mm}$-thick sheets were directly cut without further heat treatment into $30 \times 20 \mathrm{~mm}^{2}$ rectangular samples and immersed for $1 \mathrm{~h}$ at $1093 \mathrm{~K}$ into a $\mathrm{Mg}$ high-purity melt bath. He atmosphere was used to give $\mathrm{FeCr}-\mathrm{Mg}$ a bicontinuous structure (metal-metal composites).

To create a metal-air composite, the Mg-based phase was selectively etched using highly concentrated nitric acid. This etching resulted in microporous $\mathrm{Fe}_{0.8} \mathrm{Cr}_{0.2}$ with different porosities.

To obtain the metal-polymer composites, porous samples were rinsed in ultrapure water, dried and heated at $393 \mathrm{~K}$ for $10 \mathrm{~min}$, and then kept under vacuum before polymer infiltration. Then, porous samples were immersed for 20 min under vacuum into a liquid prepolymer/hardener mixture with the reactive system introduced in stochiometric proportions.
Two types of amine hardeners were used: Jeffamine D2000 and IsoPhorone Diamine to polymerize Diglycidyl Ether of Bisphenol A (DGEBA). These gave a rubbery and glassy polymer, respectively. Curing cycles were conducted for $4 \mathrm{~h}$ at $353 \mathrm{~K}$ followed by $3 \mathrm{~h}$ at $398 \mathrm{~K}$ or $2 \mathrm{~h}$ at $353 \mathrm{~K}$ followed by $2 \mathrm{~h}$ at $433 \mathrm{~K}$. Neat polymers were also polymerized.

Infiltration Characterization: TCA was carried out using a Q500 thermogravimeter analyzer (TA instruments) from 293 to $973 \mathrm{~K}$ in nitrogen atmosphere with a heating rate of $20 \mathrm{~K} \cdot \mathrm{min}^{-1}$ on around $20 \mathrm{mg}$ samples, corresponding to a tiny part of the whole sample. To check if infiltration was homogeneous, the reproducibility was checked on several infiltrated samples.

DSC was operated on a Q20 (TA instrument) at a nitrogen flow of $50 \mathrm{~mL} \cdot \mathrm{min}^{-1}$ with $5 \mathrm{mg}$ samples encapsulated in Al hermetic capsules and air as a reference sample. Glassy polymer systems were heated from room temperature to $253 \mathrm{~K}$ and rubbery polymer systems were heated from 200 to $433 \mathrm{~K}$ with a $10 \mathrm{~K} \mathrm{~min}^{-1}$ rate. The glass transition temperatures were determined by the "tangents" method on the second heating ramp to measure the glass transition temperature after conducting curing.

The sample morphology was investigated with an SEM (Tescan VEGA 3, Czech Republic) and images were analyzed by using Fiji image analysis software.$^{[4]}$ Cross-section observations were prepared using llion II (Gatan, USA).

Experimental Mechanical Characterization: Nanoindentation tests were conducted using a Nanoindenter Agilent G200 device (Agilent Technologies, USA). On each type of samples at least two batches of nine indents were conducted with a continuous stiffness measurement mode (CSM) using a Berkovich diamond tip for a maximum depth of $5 \mu \mathrm{m}$ on composite samples and $10 \mu \mathrm{m}$ on porous samples. The results were analyzed using Nanosuite software and the Berkovitch tip was calibrated by indentation on a fused silica sample. Samples were mechanically polished up to 2000 abrasive papers and then finished with a $3 \mu \mathrm{m}$ diameter and then a $1 \mu \mathrm{m}$ polycrystalline diamond abrasive.

Compression tests were conducted at room temperature on a standard tensile/compressive machine (Instron 5967, High Wycombe,UK), with a load sensor of $30 \mathrm{kN}$ on a $9 \mathrm{~mm}^{2}$ surface area and $1 \mathrm{~mm}$ height sample at a deformation rate of $3.10^{-4} \mathrm{~s}^{-1}$ The deformation measurement was carried out with a digital video extensor system. At least two curves for each sample were recorded but for the sake of conciseness only one is shown. In the case of porous samples, a load-unload cycle was conducted after every $100 \mu \mathrm{m}$ displacements. Tests were stopped far from failure after a displacement of the cross head of $0.7 \mathrm{~mm}$. The yield stress was measured at the knee between the elastic and plastic part.

Numerical Mechanical Characterization: The Hashin and Shtrikman model boundaries and simulated values were calculated using parameters shown in Table 4. For the Hashin and Shtrikman model, boundary equations (4.1 to 4.4 ) were exploited. ${ }^{[48]}$ The simulated values were calculated using a micromechanical approach. The spectral micromechanical approach is a well-established numerical method, allowing to compute strain and stress fields in multiphase materials. It relies on a description of the multiphase material in the Fourier space where the equations of linear elasticity can be solved analytically if the elastic constants are homogeneous in space. ${ }^{[49,50]}$ In the present situation, the elastic constants depend on the phase and are therefore inhomogeneous. In this situation, the equations of elasticity can be solved numerically following the method proposed by Moulinec and Suquet, consisting of using an iterative fixed point method converging to the elastic equilibrium. ${ }^{[39]}$ More recently, this method has been extended to allow for applied stress in a self-consistent

Table 4. Mechanical properties taken to calculate theoretical values.

Bulk modulus [GPa] Shear modulus [GPa] Poisson ratio

\begin{tabular}{lccc}
\hline FeCr phase & 160 & 82 & 0.29 \\
Mg phase & 35 & 17 & 0.29 \\
Glassy polymer phase & 6.2 & 1.2 & 0.4 \\
\hline
\end{tabular}




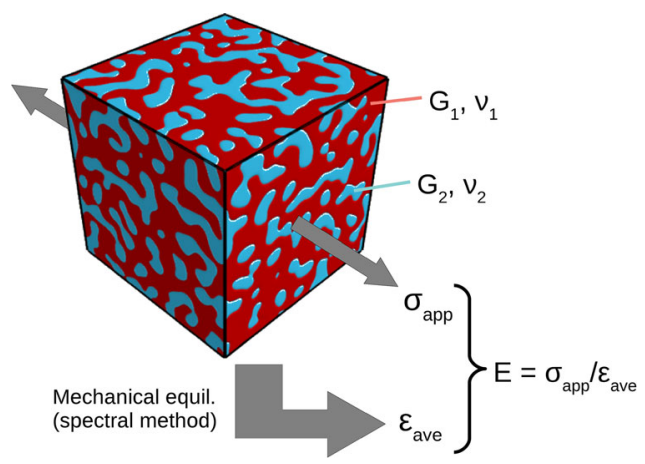

Figure 4. Schematic of the simulated method.

manner. ${ }^{[40]}$ Based on this method, we used the following steps to compute elastic constants (cf. Figure 4): 1) Connected bincontinuous microstructures are generated by a spinodal decomposition model. These artificial microstructures are known to share a lot of similarities with those obtained by dealloying. 2) Attribute an elastic constant to the different phases. We assume that the different phases are elastically isotropic. 3) Apply a finite stress to the structure and solve the stress and strain fields using the algorithm described by Gaubert et al. $\left.{ }^{[40]} 4\right)$ Young's modulus is then simply obtained by the ratio between the stress and average strain.

We note that spectral methods hold a numerical advantage over finite element methods due to the inferior scaling of the latter with respect to the size of the microstructure. ${ }^{[39]}$ On the other hand, because they rely on Fourier transform, spectral methods are limited to periodic structures.

\section{Acknowledgements}

This work was supported by Région Rhone-Alpes [CMIRA 138249], Erasmus+ program (European Union), and the French ministry of research.

\section{Conflict of Interest}

The authors declare no conflict of interest.

\section{Keywords}

composite materials, liquid metal dealloying, mechanical properties, metallic foam, nanoindentation

Received: March 30, 2020

Revised: June 23, 2020

Published online: September 24, 2020

[1] J. Erlebacher, R. Seshadri, MRS Bull. 2009, 34, 561.

[2] J. Snyder, T. Fujita, M. Chen, J. Erlebacher, Nat. Mater. 2010, 9, 904.

[3] X.Y. Lang, A. Hirata, T. Fujita, M. Chen, Nat. Nanotechnol. 2011, 6, 232.

[4] L.Y. Chen, J.S. Yu, T. Fujita, M. Chen, Adv. Funct. Mater. 2009, 19, 1221.

[5] M. Mokhtari, T. Wada, C. Le Bourlot, J. Duchet-Rumeau, H. Kato, E. Maire, N. Mary, Corros. Sci. 2020, 166, 108468.

[6] M. Mokhtari, T. Wada, C. Le Bourlot, N. Mary, J. Duchet-Rumeau, H. Kato, E. Maire, Scr. Mater. 2019, 163, 5.
[7] Y. Fukuzumi, T. Wada, H. Kato, in Interface Oral Health Science (Eds: K. Sasaki, O. Suzuki, N. Takahashi), Springer, Berlin, 2016, p. 93.

[8] H. Kato, T. Wada, M. Sadeghilaridjani, in Interface Oral Health Science (Eds: K. Sasaki, O. Suzuki, N. Takahashi), Springer, Berlin, 2016, p. 35.

[9] I.V. Okulov, J. Weissmuller, J. Markmann, Sci. Rep. 2017, 7, 77.

[10] A. Okulov, A. Volegov, J. Weissmuller, J. Markmann, I. Okulov, Scr. Mater. 2018, 146, 290

[11] I. Okulov, A. Okulov, I. Soldatov, B. Luthringer, R. Willumeit-Romer, T. Wada, H. Kato, J. Weissmuller, J. Markmann, MSE:C 2018, 88, 95.

[12] T. Wada, K. Yubuta, A. Inoue, H. Kato, Mater. Lett. 2011, 65, 1076

[13] M. F. Ashby, Phil. Trans. R. Soc. A 2006, 364, 15.

[14] Nanoporous Gold: From An Ancient Technology To A High-Tech Material. RSC Nanoscience And Nanotechnology (Eds: A. Wittstock, J. Biener, J. Erlebacher, M. Baumer), The Royal Society of Chemistry, London 2012, pp. 51-68.

[15] A. Hodge, R. Doucette, M. Biener, J. Biener, O. Cervantes, A. Hamza, Mater. Res. 2009, 24, 1600.

[16] D. Farkas, A. Caro, E. Bringa, D. Crowson, Acta Mater. 2013, 61, 3249

[17] N. Briot, T. Kennerknecht, C. Eberl, T. Balk, Philos. Mag. 2014, 94, 847.

[18] J.-H. Jin, L. Kurmanaeva, H. Rosner, Y. Ivanisenko, J. Weissmuller Acta Mater. 2009, 57, 2665.

[19] L. J. Gibson, M. F. Ashby, Cellular Solids: Structure And Properties, Cambridge Solid State Science Series, 2nd éd, Cambridge University Press, Cambridge UK 1997.

[20] J. Weissmuller, R. C. Newman, H.-J. Jin, A. Hodge, J. Kysar, MRS Bull. 2009, 34, 577.

[21] N. Mameka, K. Wang, J. Markmann, E. Lilleodden, J. Weissmuller, Mater. Res. Lett. 2016, 4, 27.

[22] A. Hodge, J. Biener, J. Hayes, P. Bythrow, C. Volkert, A. Hamza, Acta Mater. 2007, 55, 1343.

[23] I. McCue, S. Ryan, K. Hemker, X. Xu, N. Li, M. Chen, J. Erlebacher, Adv. Mater. Eng. 2016, 18, 46.

[24] K. Wang, J. Weissmuller Adv. Mater. 2013, 25, 1280.

[25] K. Wang, A. Kobler, C. Kübel, H. Jelitto, G. Schneider,J. Weissmuller, NPG Asia Mater. 2015, 7, el87.

[26] I.V. Okulov, P.-A. Geslin, I.V. Soldatov, H. Ovri, S.-H. Joo, H. Kato, Scr. Mater. 2019, 163, 133

[27] T. Wada, H. Kato, Scr. Mater. 2013, 68, 723

[28] M. Mokhtari, C. Le Bourlot, J. Adrien, A. Bonnin, T. Wada, J. DuchetRumeau, H. Kato, E. Maire, Mater Charact. 2018, 144, 166.

[29] C. Zhao, T. Wada, V. De Andrade, G. J. Williams, J. Gelb, L. Li, J. Thieme, H. Kato, Y.-C. K. Chen-Wiegart, ACS Appl. Mater. Interfaces 2017, 9, 34172 .

[30] J.-P. Pascault, R. Williams, Epoxy Polymers: New Materials And Innovations. Wiley-VCH, Weinheim 2009.

[31] E. Ernault, E. Richaud, B. Fayolle, Polym. Degrad. Stab. 2017, 138, 82.

[32] D. Knorr, J. Yu, A. Richardson, M. Hindenlang, I. McAninch, J. L. Scala, J. Lenhart, Polymer 2012, 53, 5917.

[33] L. Le Pluart, J. Duchet, H. Sautereau, Polymer 2005, 46, 12267.

[34] J. H. Westbrook, H. Conrad, The Science Of Hardness Testing And Its Research Applications, American Society for Metals, Materials Park, $\mathrm{OH} 1973$.

[35] I. McCue, B. Gaskey, B. Crawford, J. Erlebacher, Appl. Phys. Lett. 2016, 109, 231901.

[36] N. Badwe, X. Chen, K. Sieradzki, Acta Mater. 2017, 129, 251.

[37] N. Huber, R. Viswanath, N. Mameka, J. Markmann, J. Weißmüller, Acta Mater. 2014, 67, 252.

[38] N. Winter, M. Becton, L. Zhang, X. Wang, Adv. Eng. Mater. 2016 18,632 .

[39] H. Moulinec, P. Suquet. Comput. Methods Appl. Mech. Eng. 1998 157,69 
[40] A. Gaubert, Y. Le Bouar, A. Finel, Philos. Mag. 2010, 90, 3375.

[41] M. Laurent-Brocq, E. Bejanin, Y. Champion, Scanning 2015, 37, 350.

[42] X.-S. Sun, G.-K. Xu, X. Li, X.-Q. Feng, H. Gao, J. Appl. Phys. 2013, 113, 023505.

[43] N. Beets, D. Farkas, JOM 2018, 70, 2185.

[44] N. Beets, J. Stuckner, M. Murayama, D. Farkas, Acta Mater. 2020 185, 257.

[45] L.Z. Liu, X.L. Ye, H.J. Jin, Acta Mater. 2016, 118, 77.
[46] K. Hu, M. Ziehmer, K. Wang, E. Lilleodden, Philos. Mag. 2016, 96, 3322.

[47] J. Schindelin, I. Arganda-Carreras, E. Frise, Nat. Methods 2012, 9, 676.

[48] Z. Hashin, S. Shtrikman, J. Mech. Phys. Solids 1963, 11, 127.

[49] A.G. Khachaturyan, Theory Of Structural Transformations In Solids John Wiley \& Sons Inc., Weinheim 1983.

[50] T. Mura, Micromechanics Of Defects In Solids, 2nd ed., Martinus Nijhoff, Leiden, The Netherlands 1987. 